\title{
How does seminal plasma fatty-acid binding protein-9 level change in infertile males?
}

\author{
E. MENEVSE ${ }^{1 *}$ (D), R. SEVINC 1 , D. DURSUNOGLU², N. AKDAM ${ }^{3}$ and \\ E.N. KORUCU ${ }^{4}$
}

\footnotetext{
${ }^{1}$ Department of Medical Biochemistry, Medicine Faculty, Selcuk University, Konya, Turkey

${ }^{2}$ Department of Histology and Embryology, Medicine Faculty, Selcuk University, Konya, Turkey

${ }^{3}$ Department of Biostatistics, Medicine Faculty, Selcuk University, Konya, Turkey

${ }^{4}$ Department of Molecular Biology and Genetics, Science Faculty, Necmettin Erbakan University, Konya, Turkey
}

Received: January 15, 2020 - Accepted: July 10, 2020

Published online: October 3, 2020

(๔ 2020 Akadémiai Kiadó, Budapest

\section{ABSTRACT}

In recent years, free fatty acid binding proteins (FABPs) are implicated in spermatogenesis and sperm morphology. FABPs are members of the intracellular lipid-binding protein family; they exhibit tissue specific expression like the FABP9/PERF15 (Perforated15) male germ cell-specific fatty acid linkage-protein.

The aim of the study was to assess the levels of seminal FABP-9 in normozoospermic and oligozoospermic men, and the possible relations between seminal FABP-9 levels and semen parameters.

Research was carried out on 60 male volunteers who were admitted to Selcuk University Faculty of Medicine of Andrology Laboratory. Normozoospermic individuals $(n=30)$ were identified as Group 1, and Oligozoospermic individuals $(n=30)$ were identified as Group 2. The semen samples were collected in sterile plastic containers. Sperm parameters were assessed according to Kruger's criteria. Seminal plasma FABP-9 levels were analyzed by ELISA method. Outcomes were statistically evaluated at 0.05 significance level with SPSS (22.0). The Receiver Operating Characteristic (ROC) curve was used to evaluate the performance of FABP-9 levels as compared to that of the concentration and motility data of the sperm. FABP-9 levels were significantly higher in normozoospermic individuals $(3.41 \pm 1.64 \mathrm{ng} / \mathrm{mL})$ than in oligozoospermic individuals $(1.99 \pm 0.78 \mathrm{ng} / \mathrm{mL})$. There were significant correlations between FABP-9 levels and sperm concentration, total sperm count, motility, progressive motility, immobility, Total Progressive Motil Sperm Count (TPMSC), head anomaly, and teratozoospermia index.

\footnotetext{
* Corresponding author. Department of Medical Biochemistry, Selcuk University Medicine Faculty, Aleddin Keykubat Campus, Konya, Turkey, Tel.: +90 533 7484622; fax: +90 332 2412184. E-mail: esmenevse@yahoo.com
} 
We suggest that FABP-9 level is an important biomarker, and low levels of semen FABP-9 may impact the fertility status based on the ROC findings.

\section{KEYWORDS}

infertile male, semen, fatty acid binding protein-9, spermyogram, fertility

\section{INTRODUCTION}

Fatty acid binding proteins (FABPs) are members of the intracellular lipid-binding protein family, and exhibit tissue-specific expression [1, 2]. FABPs are small $(14-15 \mathrm{kDa})$ cytosolic proteins that bind to unsaturated and saturated long-chain fatty acids (LCFAs), eicosanoids and other lipids with high affinity [3, 4]. FABPs are known to be intracellular lipid chaperones facilitating lipid distribution and responses. FABPs are key mediators in the regulation of metabolic and inflammatory pathways inside the cell. FABPs also bind to intracellular hydrophobic ligands such as retinol, retinoic acid, bile salts and pigments [5].

Members of the FABP family show a wide primary structure homology ranging from 20 to $70 \%$ similarity of the amino acid sequences. There are minor structural differences between isoforms; ligand selectivity and differences in binding activities (binding affinity and mechanisms) that allow binding of long-chain fatty acids $[6,7]$.

FABPs are involved in lipid transfer to some compartments in the cell, such as to lipid droplets for storage, to the endoplasmic reticulum for trafficking, signaling and membrane synthesis, to mitochondria and peroxisomes for oxidation, to regulate the activity of cytosolic enzymes, to the nucleus to regulate transcription of genes related to lipids through binding to nuclear hormone receptors (NHRs). FABPs take a role as signaling molecules even outside the cell [6-10]. The regulation of these diverse processes is accompanied by the expression of multiple FABPs and may be driven by protein-protein and protein-membrane interactions [7].

Recent cell culture studies have demonstrated that FABPs potentially affect the uptake, storage and extracellular delivery of fatty acids, as well as cholesterol and phospholipid metabolisms [6].

It is shown that FABPs are expressed in mammalian tissue, and increase fatty acid transport in the plasma membrane $[11,12]$. Most FABPs absorb their ligands directly from the membrane except the liver isoforms of FABP [9]. FABPs bring about changes in gene expression and lipid metabolism. Therefore FABP leads to changes in whole body energy homeostasis [7]. Cytoplasmic FABPs are involved in the process of moving fatty acids from the plasma membrane into the cytoplasm [13]. In addition, it is suggested that FABPs have important functions in the transport, metabolism and storage of FA and/or protect other proteins and membranes from the effects of high FA concentrations which are potentially deleterious [14].

FABP-9/PERF15 (Perforated 15) is a male germ cell-specific fatty acid linkage protein. FABP-9 plays a role in the male reproductive system, especially in spermatogenesis. FABP-9 has been identified in the first place as the main component of the murine sperm perforatorium and perinuclear theca $[1,2]$. 
Due to FABP-9 localization in the spermatozoon, which lays between the inner acrosomal and the outer nucleus membranes, it is presumed that this protein is required for sperm development [15]. In addition, the composition of body fatty acids changes during spermatogenesis and the abnormal fatty acid composition of sperm is related to infertility. Furthermore, FABP could be influenced by changes in the composition of fatty acids $[16,17]$.

The binding affinity of FABP-9 for phospholipids of the opposite membranes of sperm's cytoplasmic organelles, i.e. acrosome and nucleus, causes mediated attachment of these membranes, which is essential for species-specific head formation and fertilization $[18,19]$.

Therefore, FABP-9 seems to have a basic role in a successful fertilization. However, the biological functions and mechanisms of FABP's action are still not fully known. The number of spermatozoa has been found to decrease significantly in the last 50 years. Furthermore, in about one third of infertile males no infertility-related factor can be identified [20-22], and their condition is defined as idiopathic infertility. Today, their medical history, physical examination and scrotal ultrasound (US) and semen analysis are standard assessments in the determination of the fertilization status of men [23]. In recent years, researchers have focused on the proteomic analysis of seminal plasma or spermatozoa, because it is well-known that the presence, abundance and post-translational modifications of proteins represent important information regarding the biology of fertilization [24]. Therefore, advances in proteomics studies have encouraged the search for new biomarkers of male infertility.

Based on this knowledge, the aim of our study was to determine the possible relationship between FABP-9 levels and semen parameters in infertile male individuals and the differences according to levels of FABP-9 between normozoospermic and oligozoospermic individuals. FABP-9 levels were determined as $\mathrm{ng} / \mathrm{mL}$ and $\mathrm{ng} / \mathrm{mg}$ protein. One of our aims was to show whether FABP-9 levels calculated as ng/mg protein could be a stronger differential diagnosis than that calculated as $\mathrm{ng} / \mathrm{mL}$. In addition, we aimed to find a correlation between FABP-9 levels calculated per mg semen protein and the performance of FABP-9 as a diagnostic test by assessment with the Receiver Operating Characteristic curve (ROC).

\section{MATERIALS AND METHODS}

The study enrolled a total of 60 men in two groups, who were admitted to the IVF Center of Department of Histology and Embryology of Medicine Faculty of Selcuk University. This study was conducted with the permission of the Ethic Committee of Selcuk University with the number of 2018/20 (decision date: 17th January, 2018). All the volunteers signed the "Informed Patient Consent Form" as written informed consent in conformity with the ethical standards and the Declaration of Helsinki Principles.

Two groups were formed in the study. Normozoospermic individuals $(n=30)$ with an age range of 24-38 years were included as Group 1 (sperm concentration $\geq 15 \mathrm{million} / \mathrm{mL}$ ); Oligozoospermic individuals $(n=30)$ with an age range of $24-36$ years were included as Group 2 (sperm concentration $<15$ million/mL). Those treated with any medication and chronic illness, those with azoospermia and those who smoked were excluded from the study.

For the biochemical analysis, no extra semen samples were taken from the individuals. The remaining semen samples were used for FABP-9 determination after evaluation of the spermyogram analysis. Samples were centrifuged at $1,000 \mathrm{rpm}$ for $20 \mathrm{~min}$. The supernatants were 
removed to eppendorf tubes to be stored at $-80{ }^{\circ} \mathrm{C}$ until analyzation of the FABP-9 and protein levels.

Seminal FABP-9 was assessed by the Mybiosource ELISA test kit (cat no: MBS918033, sensitivity $0.047 \mathrm{ng} / \mathrm{mL}$, reference range $0.188-12 \mathrm{ng} / \mathrm{mL}$ ) obtained from MyBioSource, Inc., USA. The results were indicated as $\mathrm{ng} / \mathrm{mL}$ and $\mathrm{ng} / \mathrm{mg}$ protein. Total protein analysis was carried out by the BioRad colorimetric kit (cat no: 500-0002) obtained from BioRad Laboratory Inc., USA. The results were indicated as $\mathrm{mg} / \mathrm{mL}$. Biochemical characterization of FABP-9 was performed in experimental studies, with the properties of cell proteins taken into consideration. We also calculated FABP-9 values per mg seminal protein in the study. In order to calculate the FABP-9 as $\mathrm{ng} / \mathrm{mg}$ seminal protein, total protein concentration $(\mathrm{mg} / \mathrm{mL})$ is divided by FABP concentration (ng/mL). Therefore, FABP-9 values are normalized for $\mathrm{mg}$ protein based on total protein values. For the analysis, Elisa Reader (BMG LABTECH, Germany) and Elisa Washer (Rayto Microplate washer, RT2600, China) were used. Biochemical analyses were performed at Medical Biochemistry and Physiology Research Laboratories within Selcuk University. Spermyogram analysis was evaluated according to WHO 2010 Kruger criteria [25]. Spermyogram analyses were determined at Andrology Laboratory of Selcuk University.

\section{Collection of sperm samples, storage and evaluation of spermyograms}

The semen samples obtained by masturbation at the hospital after 2-6 days of abstinence were collected in special sterile plastic containers. For liquefaction, samples were incubated at $37{ }^{\circ} \mathrm{C}$ for $20 \mathrm{~min}$, and evaluated within $1 \mathrm{~h}$ of collection. Sperm parameters were assessed according to the World Health Organization 2010 criteria [25] (semen volume $1.5 \mathrm{~mL}$; sperm concentration 15 million/mL; total sperm count 39 million; total sperm motility 40\%; progressive sperm motility $32 \% \mathrm{~A} \pm \mathrm{B}$; and sperm morphology $4 \%$ Kruger criteria) and the results were recorded. Smear preparations from semen samples were prepared and stained with 'Spermac' stain for morphological evaluations. The percentages of normal and abnormal spermatozoa forms were determined by scoring at least 100 spermatozoa per preparation.

\section{STATISTICAL ANALYSIS}

Statistical analyses were carried out with the SPSS program (version 22.0). The results were described as minimum, maximum, mean $\pm \mathrm{SD}$ and median. Independent- $\mathrm{T}$ test was used to compare differences between two independent groups when normally distributed. MannWhitney $U$ test was used when the groups were not normally distributed. Spearman and Pearson correlations were used to assess the relationships between FABP-9 and semen parameters. Outcomes were statistically evaluated at 0.05 significance level ( $95 \%$ confidence level). We calculated the ROC curve, which is a graphical statistical method used to evaluate the performance of diagnostic tests. The ROC curve is created at various threshold settings by plotting the true positive rate against the false positive rate. The true-positive rate is known as sensitivity, the false-positive rate is known as 1-specificity. The ROC curve determines the optimal cut-off point and compares the performances of different diagnostic tests. ROC curves were drawn according to the sensitivity and 1-specificity values of each diagnostic test. The areas under the curve (AUC) were calculated. The SPSS 22.0 statistical package program was used for the ROC curve method, and the results were evaluated at 5\% significance level ( $95 \%$ confidence). 


\section{RESULTS}

In the present study the mean age of the individuals in Group 1 was $31.16 \pm 6.36$ years and in Group 2 it was $29,66 \pm 4.90$ years $\left(P^{>} 0.05\right)$. As shown in Table 1, the concentration of FABP-9 was significantly higher more than 1.5-fold in Normozoospermic individuals $(3.40 \pm 1.64 \mathrm{ng} /$ $\mathrm{mL})$ than in Oligozoospermic individuals $(1.99 \pm 0.78 \mathrm{ng} / \mathrm{mL})$. Furthermore, the concentration of FABP-9 (ng/mg protein) was significantly higher (more than 3.5-fold) in Group 1 (0.70 \pm $0.37 \mathrm{ng} / \mathrm{mg}$ protein), compared to Group $2(0.20 \pm 0.09 \mathrm{ng} / \mathrm{mg}$ protein). Total protein levels were $10.60 \pm 2.6 \mathrm{mg} / \mathrm{mL}$ in Group 1 and $5.18 \pm 1.42 \mathrm{mg} / \mathrm{mL}$ in Group 2. The differences were statistically significant.

The findings of the spermyogram analysis are shown in Table 2. The values of sperm concentration, total number, total motility, progressive motility, non progressive motility, immobility, Total Progressive Motil Sperm Count (TPMSC), normal morphology, head anomaly, neck and tail anomaly, neck and middle part anomaly significantly differed between the groups of Normozoospermic and Oligozoospermic individuals.

Correlation coefficient values and $P$-values of all groups are shown in Table 3. FABP-9 (ng/ $\mathrm{mL}$ ) levels correlated significantly with Concentration, Total Number, Total Motility, Progressive Motility, Immotility and TPMSC. In addition, FABP-9 levels calculated as per mg protein were correlated with sperm Concentration, Total Number, Total Motility, Progressive Motility, Non-Progressive Motility, Immotility, TPMSC, Normal Morpholgy, Head Anomaly, Neck Middle Part Anomaly and Teratozoospermia Index.

As it well-known, Spermyogram analyses are used to determine whether or not an individual is infertile, and are important markers today. In addition to these diagnostic tests, we evaluated the performance of FABP-9 levels as compared to data of concentration and motility of the sperm, which are currently used for evaluation. The ROC curve is shown in Fig. 1.

In Fig. 1, ROC curves were plotted according to sensitivity and 1-specificity values for 4 different diagnostic tests and were given as the areas in the following Tables 4 and 5 .

In Fig. 1, sensitivity and specificity of FABP-9 (ng/mL), FABP-9 (ng/mg protein), sperm concentration and motility are compared at different decision points. It is important to note that these are the least false positive at the highest susceptibility points; FABP-9 (ng/mg protein) reaches to the 0.964 threshold and motility to the 0.823 threshold at its highest determinant. When we sort the positive determinants from highest to lowest according to the AUC values, the order is sperm concentration, FABP-9 (ng/mg protein), motility and FABP-9 (ng/mL). Thus, the

Table 1. Seminal plasma FABP-9 and total protein concentrations of the groups

\begin{tabular}{llccccccc}
\hline \multirow{2}{*}{ Groups } & \multicolumn{3}{c}{ Normozoospermic $(n=30)$} & & \multicolumn{3}{c}{ Oligozoospermic $(n=30)$} \\
\cline { 2 - 3 } & Min-Max & Median & Mean \pm SD & & Min-Max & Median & Mean \pm SD \\
\hline FABP-9 $(\mathrm{ng} / \mathrm{mL})$ & $1.17-7.21$ & 3.41 & $3.40 \pm 1.64^{*}$ & & $0.54-3.05$ & 1.85 & $1.99 \pm 0.78$ \\
FABP-9 $(\mathrm{ng} / \mathrm{mg}$ protein) & $0.27-1.54$ & 0.60 & $0.70 \pm 0.37^{*}$ & & $0.07-0.39$ & 0.20 & $0.20 \pm 0.09$ \\
Total protein $(\mathrm{mg} / \mathrm{mL})$ & $5.78-15.92$ & 11.01 & $10.60 \pm 2.6^{* *}$ & & $1.98-8.64$ & 5.11 & $5.18 \pm 1.42$ \\
\hline
\end{tabular}

${ }^{\star} P=0.000 \leq \alpha=0.05$ vs. normozoospermic and oligozoospermic group. FABP9- Fatty acid binding protein-9. $n$ - number of the individuals; Min-minimum; Max-maximum; ${ }^{*} P=0.000 \leq \alpha=0.01$ vs. normozoospermic and oligozoospermic group. 
Table 2. Sperm parameters and incidences of morphologic anomalies in the normozospermic and oligozospermic groups (mean $\pm \mathrm{SD}$ )

\begin{tabular}{|c|c|c|c|}
\hline Sperm parameters & Normozoospermic & oligozoospermic & $P$-value \\
\hline Volume (mL) & $3.64 \pm 1.47$ & $4.28 \pm 1.51$ & 0.071 \\
\hline Concentration (million/mL) & $54.27 \pm 22.33$ & $4.69 \pm 4.41$ & $0.000^{* *}$ \\
\hline Total number (million) & $187.71 \pm 82.27$ & $20.51 \pm 20.81$ & $0.000^{* *}$ \\
\hline Total motility (\%) & $73.41 \pm 7.97$ & $61.89 \pm 11.14$ & $0.000^{\star *}$ \\
\hline Progressive motility (\%) & $59.72 \pm 10.85$ & $39.69 \pm 15.05$ & $0.000^{* *}$ \\
\hline Non progressive motility (\%) & $13.69 \pm 3.74$ & $20.35 \pm 7.82$ & $0.001^{\star *}$ \\
\hline Immotility (\%) & $26.59 \pm 4.31$ & $37.30 \pm 10.48$ & $0.000^{* *}$ \\
\hline TPMSC (million) & $115.66 \pm 55.80$ & $8.99 \pm 10.51$ & $0.000^{* *}$ \\
\hline Normal morpholgy (\%) & $2.10 \pm 0.61$ & $1.38 \pm 0.52$ & $0.010^{* *}$ \\
\hline Head anomaly (\%) & $88.77 \pm 1.91$ & $91.00 \pm 1.60$ & $0.004^{\star *}$ \\
\hline Amorphous head (\%) & $76.93 \pm 3.28$ & $79.25 \pm 4.52$ & 0.110 \\
\hline Large head (\%) & $4.37 \pm 2.25$ & $5.50 \pm 4.81$ & 0.610 \\
\hline Small head (\%) & $2.37 \pm 1.63$ & $2.13 \pm 1.81$ & 0.739 \\
\hline Long head (\%) & $4.33 \pm 3.11$ & $3.63 \pm 2.39$ & 0.555 \\
\hline Multiple head (\%) & $0.77 \pm 1.48$ & $0.50 \pm 0.76$ & 0.930 \\
\hline Neck and tail anomaly & $9.07 \pm 1.82$ & $7.63 \pm 1.30$ & $0.034^{*}$ \\
\hline Neck middle part anomaly & $12.67 \pm 2.51$ & $16.88 \pm 3.27$ & $0.000^{\star *}$ \\
\hline Tail anomaly (\%) & $14.60 \pm 3.77$ & $13.75 \pm 2.82$ & 0.557 \\
\hline Double tail (\%) & $1.30 \pm 1.12$ & $1.13 \pm 1.55$ & 0.720 \\
\hline Tail stump (\%) & $0.47 \pm 0.68$ & $0.38 \pm 0.74$ & 0.686 \\
\hline Dag defect (\%) & $6.67 \pm 2.70$ & $6.38 \pm 2.45$ & 0.792 \\
\hline Long tail (\%) & $0.40 \pm 0.72$ & $0.43 \pm 0.79$ & 0.955 \\
\hline Short tail (\%) & $5.83 \pm 1.88$ & $5.50 \pm 1.51$ & 0.562 \\
\hline Teratozoospermia index & $1.28 \pm 0.052$ & $1.31 \pm 0.032$ & 0.058 \\
\hline
\end{tabular}

${ }^{\star} P=0.000 \leq \alpha=0.05$ vs. normozoospermic and oligozoospermic group.

${ }^{*} P=0.000 \leq \alpha=0.01$ vs. normozoospermic and oligozoospermic group.

data show that the concentration of FABP-9 is a very important determinant that cannot be ignored.

AUC values of each test were found statistically significant. The highest area was found to be Sperm Concentration and the smallest area, FABP-9 $(\mathrm{ng} / \mathrm{mL})$ test. The $P$-values for comparison of the diagnostic tests are given in Table 5.

There was no statistically significant difference between sperm concentration and FABP-9 (ng/mg protein) tests $(P=0.0722>\alpha=0.05)$. Similarly, there was no statistically significant difference between Motility and FABP-9 $(\mathrm{ng} / \mathrm{mL})$ diagnostic tests $(P=0.1516>\alpha=0.05)$. Differences between other diagnostic tests were found to be statistically significant $(P \leq \alpha=0.05)$. Therefore, our findings indicate that FABP-9 (ng/mg protein) levels can be used as a biochemical test with the diagnosis based on semen motility values in determining the normozoospermic or oligozoospermic status of individuals. These findings also indicate that FABP-9 (ng/mg protein) (0.964) is more predictive than motility $(0.823)$ when evaluated on the basis of AUC value. 
Table 3. The Correlations between FABP-9 (ng/mL), FABP-9 (ng/mg protein) concentrations and Semen Parameters in the combined groups $(n=60)$

\begin{tabular}{|c|c|c|c|c|}
\hline \multirow[b]{2}{*}{ Sperm parameters } & \multicolumn{2}{|c|}{ FABP-9 $(\mathrm{ng} / \mathrm{mL})$} & \multicolumn{2}{|c|}{$\mathrm{FABP}(\mathrm{ng} / \mathrm{mg}$ protein) } \\
\hline & $r$ & $P$ & $r$ & $P$ \\
\hline Volume (mL) & -0.079 & 0.554 & -0.174 & 0.187 \\
\hline Concentration (million/mL) & 0.491 & $0.000^{\star}$ & 0.753 & $0.000^{*}$ \\
\hline Total number (million) & 0.471 & $0.000^{*}$ & 0.719 & $0.000^{*}$ \\
\hline Total motility (\%) & 0.275 & $0.039^{*}$ & 0.508 & $0.000^{\star}$ \\
\hline Progressive motility (\%) & 0.300 & $0.021^{\star}$ & 0.538 & $0.000^{*}$ \\
\hline Non progressive motility (\%) & -0.047 & 0.729 & -0.278 & $0.035^{\star}$ \\
\hline Immotility (\%) & -0.274 & $0.039^{\star}$ & -0.508 & $0.000^{*}$ \\
\hline TPMSC (million) & 0.349 & $0.007^{\star}$ & 0.621 & $0.000^{*}$ \\
\hline Normal morpholgy (\%) & 0.207 & 0.213 & 0.452 & $0.004^{*}$ \\
\hline Head anomaly & -0.148 & 0.376 & -0.416 & $0.009^{*}$ \\
\hline Amorphous head (\%) & -0.020 & 0.903 & -0.152 & 0.363 \\
\hline Large head (\%) & -0.025 & 0.887 & -0.079 & 0.647 \\
\hline Small head (\%) & 0.171 & 0.312 & 0.261 & 0.118 \\
\hline Long head (\%) & -0.122 & 0.467 & -0.103 & 0.539 \\
\hline Multiple head (\%) & -0.091 & 0.593 & 0.011 & 0.948 \\
\hline Neck and tail anomaly & 0.086 & 0.610 & 0.268 & 0.103 \\
\hline Neck middle part anomaly & -0.209 & 0.207 & -0.411 & $0.010^{*}$ \\
\hline Tail anomaly (\%) & -0.202 & 0.223 & -0.177 & 0.288 \\
\hline Double tail (\%) & -0.308 & 0.060 & -0.159 & 0.341 \\
\hline Tail stump (\%) & -0.316 & 0.053 & -0.220 & 0.184 \\
\hline Dag defect (\%) & -0.040 & 0.786 & 0.032 & 0.850 \\
\hline Long tail (\%) & -0.094 & 0.581 & -0.138 & 0.414 \\
\hline Short tail (\%) & 0.136 & 0.416 & 0.018 & 0.914 \\
\hline Teratozoospermia index & -0.094 & 0.576 & -0.350 & $0.031^{\star}$ \\
\hline
\end{tabular}

${ }^{\star} P \leq 0.05$; FABP-9 - Fatty acid binding protein-9. TPMSS - Total progressively motile sperm count.

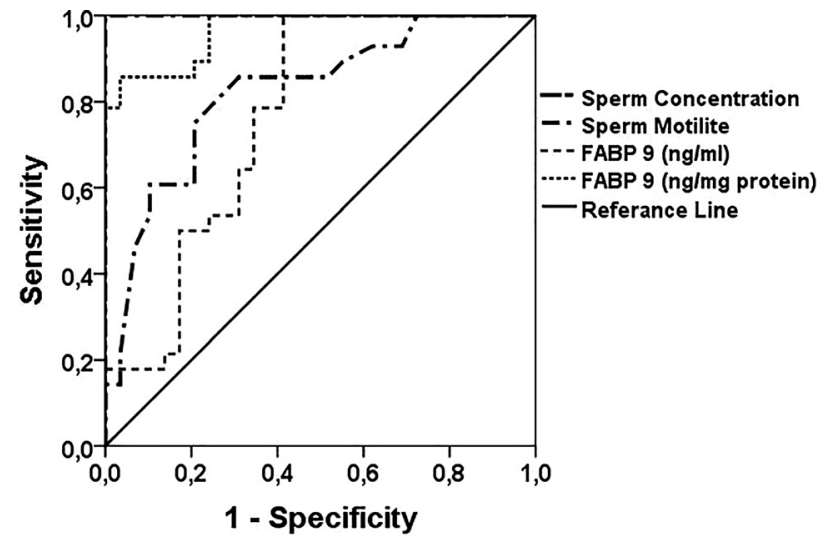

Fig. 1. ROC curve 
Table 4. ROC curve fields and $P$-values

\begin{tabular}{lcc}
\hline & Area under curve (AUC) & $P$-value \\
\hline Sperm concentration & 1.000 & 0.000 \\
FABP-9 (ng/mg protein) & 0.964 & 0.000 \\
Sperm motility & 0.823 & 0.000 \\
FABP-9 (ng/mL) & 0.766 & 0.001 \\
\hline
\end{tabular}

FABP-9 - Fatty acid binding protein-9.

Table 5. $P$-values for comparison of diagnostic tests and FABP-9 measurements

\begin{tabular}{lcccc}
\hline & $\begin{array}{c}\text { Sperm } \\
\text { concentration }\end{array}$ & $\begin{array}{c}\text { Sperm } \\
\text { motility }\end{array}$ & $\begin{array}{c}\text { FABP-9 }(\mathrm{ng} / \\
\mathrm{mL})\end{array}$ & $\begin{array}{c}\text { FABP-9 }(\mathrm{ng} / \mathrm{mg} \\
\text { protein) }\end{array}$ \\
\hline $\begin{array}{l}\text { Sperm } \\
\text { concentration }\end{array}$ & - & 0.0015 & 0.0004 & 0.0722 \\
Sperm motility & - & - & & 0.1516 \\
FABP-9 $(\mathrm{ng} / \mathrm{mL})$ & - & - & - & 0.0003 \\
\hline
\end{tabular}

FABP-9 - Fatty acid binding protein-9.

\section{DISCUSSION}

As is known, if a high percentage of spermatozoa are abnormal, fertility decreases [26]. Therefore, spontaneous germ cell death, which eliminates defective or unnecessary germ cells, can be considered a quality control mechanism [16]. It was found that FABP-9 was initially expressed in programmed cell death of spermatoids [27].

Research shows that changes in fatty acid composition during spermatogenesis and abnormal fatty acid composition in sperm lead to infertility [17]. In addition, it seems that the protein could have an influence on programmed death of spermatocytes and development as well as a protective role against oxidation of sperm fatty acids (FA), which in turn increases fertility potential, thus maintaining their ability to fertilize oocytes [27].

On the other hand, FABP-9 is one of the members of the FABP gene family found only in the mammalian genome $[15,28]$. In a recent study, it was shown that the absence of sperm FABP-9 affects the sperm morphology of mice [2].

Jamshidi et al. (2014) studied potential mutations in FABP-9 of infertile men which could affect human sperm morphology and fertility and provided evidence showing that FABP-9 may be effective in spermatogenesis, sperm shaping and perhaps human fertility. However, they did not observe any mutations in the exonic coding regions. They did not analyze the promoter or introns 1 and 2; they recommended analyzing the promoter. Thus conclusions regarding the relations of these genes with sperm dysmorphology and the role of FABP-9 in reproduction are still unavailable [1]. However, genes involved in the development of sperm morphology have been identified (globozoospermia 15). It is thought that they may be used as a markers. Therefore, it seems that finding candidate genes for use as genetic markers is the right approach in the diagnosis of male infertility [1]. 
As is known, the testis is a gonad composed of different sections and cell types. Although FABP-9 has been shown to be expressed in the testis, according to Jamsidi et al. (2014) there is no evidence to show the specific role of gene expression in the human testis. Possibly, the protein is expressed in a different type of human testicular cell, such as interstitial tissue cells. Due to the importance of the role of interstitial tissue protein induction which supports meiosis, growth and synchronization of germ cells in Leydig cells, FABP-9 may contribute an indispensable and still unknown role in human fertility. Due to their limited research on human FABP-9, Jamshidi et al. (2014) could not determine the exact function of the protein and the related mechanism in humans [1]. However, Selveraj et al. (2010) reported that FABP-9 could be detected up to the 16th day of testicular development, but marked expression could only be seen in late-prolonging spermatids in mice [2]. Mice lacking FABP-9 developed sperm head abnormalities but were fertile. They show increased morphological defects in their sperm structure relative to wild-type mice [2]. Sosnin et al. (2019) performed a study on blood serum and seminal plasma of healthy and oligozoospermic men. According to their findings, seminal plasma FABP-9 levels were higher in the healthy group than in infertile men $(P=0.01082)$, but serum levels did not show any differences between the groups [29].

Our findings are similar to those reported by Kido et al. [27], Selveraj et al. [2] and Sosnin et al. [29]. Our findings on relationships between FABP-9 levels and sperm motility as well as sperm anomalies in infertile individuals are also consistent with the results of Pouresmaeili et al. [30]. Their study is the first to report that FABP-9 is found in the sperm head, between the inner acrosome and the outer nuclear membrane [30]. In our study, we elucidated the possible relationships between testicular fatty acid binding protein levels and semen parameters in infertile individuals. The other important result of our study is that, whereas FABP-9 levels (ng/mg protein) decrease in seminal plasma, the percentage of sperm with normal morphology also decreases. In addition, the teratozoospermia index, i.e. the number of morphological anomalies per sperm increases significantly. Our results of significant relationships between FABP-9 and semen parameters, and the significant difference between normozoospermic and oligozoospermic individuals in terms of FABP-9 (ng/mL) and FABP-9 (ng/mg protein) levels support the assumption that FABP-9 might be a biomarker. Positive relationship between FABP-9 levels and sperm motility might be a sign of the sperm's protection from damage by toxins, drugs, and chemicals. As a result, there are significant differences between groups of normozoospermic and oligozoospermic individuals according to FABP-9 values. FABP-9 levels were lower in oligozoospermic males, and correlated with the majority of semen parameters. We presume that this protein is required for fertilization. We suggest that, based on its significant correlation with the results of spermiograms, FABP-9 level might be a biomarker. Low FABP-9 levels in the semen may also reflect the fertilization status.

Another important finding of our study is that FABP-9 levelscalculated as per mg protein are more accurate than those calculated as $\mathrm{ng} / \mathrm{mL}$.

Information about the mechanism of FABP-9 which is thought to have a role in fertilization is limited in the world literature. The present study is the first biochemical study that evaluates the importance of FABP-9 on the basis of ROC curves in the semen of individuals with Normozoospermia and Oligozoospermia.

\section{CONCLUSION}

Our results show that FABP-9 is associated with the mechanism of fertility. FABP-9 may contribute a new approach for future studies on the biochemical mechanisms of male infertility 
and on the development of therapeutic modality. The diagnostic and prognostic criteria of the fertilization status are currently fulfilled by the spermyogram. According to our result, FABP-9 levels provide analysis results equivalent with those of a spermyogram test.

Conflict of interest: None of the authors have conflict of interest.

\section{ACKNOWLEDGMENTS}

The research was funded by Selcuk University Scientific Research Project Coordinator (project no: 18202008).

\section{REFERENCES}

1. Jamshidi J, Pouresmaeili F, Darvish H, Omrani MD, Azargashb E, Sadeghi MR, et al. FABP9 mutations are not detected in cases of infertility due to sperm morphological defects in Iranian men. Int J Fertil Steril 2014; 7(4): 275-80. Epub 2014/02/13. PubMed PMID: 24520497; PubMed Central PMCID: PMCPMC3901177.

2. Selvaraj V, Asano A, Page JL, Nelson JL, Kothapalli KS, Foster JA, et al. Mice lacking FABP9/PERF15 develop sperm head abnormalities but are fertile. Dev Biol 2010; 348(2): 177-89. Epub 2010/10/06. PubMed PMID: 20920498; PubMed Central PMCID: PMCPMC2982899. https://doi.org/10.1016/j.ydbio.2010.09.019.

3. Coe NR, Bernlohr DA. Physiological properties and functions of intracellular fatty acid-binding proteins. Biochem Biophys Acta 1998; 1391(3): 287-306. Epub 1998/06/20. PubMed PMID: 9555061. https://oi.org/ 10.1016/s0005-2760(97)00205-1.

4. Zimmerman AW, Veerkamp JH. New insights into the structure and function of fatty acid-binding proteins. Cell Mol Life Sci 2002; 59(7): 1096-116. Epub 2002/09/12. PubMed PMID: 12222958. https://doi.org/10.1007/ s00018-002-8490-y.

5. Corsico B, Liou HL, Storch J. The alpha-helical domain of liver fatty acid binding protein is responsible for the diffusion-mediated transfer of fatty acids to phospholipid membranes. Biochemistry 2004; 43(12): 3600-7. Epub 2004/03/24. PubMed PMID: 15035630. https://doi.org/10.1021/bi0357356.

6. Furuhashi M, Hotamisligil GS. Fatty acid-binding proteins: role in metabolic diseases and potential as drug targets. Nat Rev Drug Discov 2008; 7(6): 489-503. Epub 2008/05/31. PubMed PMID: 18511927; PubMed Central PMCID: PMCPMC2821027. https://doi.org/10.1038/nrd2589.

7. Storch J, Thumser AE. Tissue-specific functions in the fatty acid-binding protein family. J Biol Chem 2010; 285(43): 32679-83. Epub 2010/08/19. PubMed PMID: 20716527; PubMed Central PMCID: PMCPMC2963392. https://doi.org/10.1074/jbc.R110.135210.

8. Graber R, Sumida C, Nunez EA. Fatty acids and cell signal transduction. J Lipid Mediat Cell Signal 1994; 9(2): 91-116. Epub 1994/03/01. PubMed PMID: 8012764.

9. Storch J, Corsico B. The emerging functions and mechanisms of mammalian fatty acid-binding proteins. Annu Rev Nutr 2008; 28: 73-95. Epub 2008/04/26. PubMed PMID: 18435590. https://doi.org/10.1146/ annurev.nutr.27.061406.093710.

10. Tan NS, Shaw NS, Vinckenbosch N, Liu P, Yasmin R, Desvergne B, et al. Selective cooperation between fatty acid binding proteins and peroxisome proliferator-activated receptors in regulating transcription. Mol Cell 
Biol 2002; 22(14): 5114-27. Epub 2002/06/22. PubMed PMID: 12077340; PubMed Central PMCID: PMCPMC139777. https://doi.org/10.1128/mcb.22.14.5114-5127.2002.

11. Hamilton JA. Fatty acid transport: difficult or easy?. J Lipid Res 1998; 39(3): 467-81. Epub 1998/04/21. PubMed PMID: 9548581.

12. Schaffer JE. Fatty acid transport: the roads taken. Am J Physiol Endocrinol Metab 2002; 282(2): E239-46. Epub 2002/01/15. PubMed PMID: 11788354. https://doi.org/10.1152/ajpendo.00462.2001.

13. Vork MM, Glatz JF, Van Der Vusse GJ. On the mechanism of long chain fatty acid transport in cardiomyocytes as facilitated by cytoplasmic fatty acid-binding protein. J Theor Biol 1993; 160(2): 207-22. Epub 1993/01/21. PubMed PMID: 8474251. https://doi.org/10.1006/jtbi.1993.1014.

14. Hsu KT, Storch J. Fatty acid transfer from liver and intestinal fatty acid-binding proteins to membranes occurs by different mechanisms. J Biol Chem 1996; 271(23): 13317-23. Epub 1996/06/07. PubMed PMID: 8662836. https://doi.org/10.1074/jbc.271.23.13317.

15. Oko R, Morales CR. A novel testicular protein, with sequence similarities to a family of lipid binding proteins, is a major component of the rat sperm perinuclear theca. Dev Biol 1994; 166(1): 235-45. Epub 1994/11/01. PubMed PMID: 7958448. https://doi.org/10.1006/dbio.1994.1310.

16. Grogan WM, Farnham WF, Szopiak BA. Long chain polyenoic acid levels in viably sorted, highly enriched mouse testis cells. Lipids 1981; 16(6): 401-10. Epub 1981/06/01. PubMed PMID: 7266265. https://doi.org/10. 1007/bf02535006.

17. Zalata AA, Christophe AB, Depuydt CE, Schoonjans F, Comhaire FH. The fatty acid composition of phospholipids of spermatozoa from infertile patients. Mol Hum Reprod 1998; 4(2): 111-8. Epub 1998/05/23. PubMed PMID: 9542967. https://doi.org/10.1093/molehr/4.2.111.

18. Farkhondeh P, Tahereh K, Mahmood JT, Mojgan B, Jamileh G, Fatemeh SN. A Novel human lipid binding protein coding gene: PERF15, sequence and cloning. J Reprod Infertil 2009; 10(3): 199-205. Epub 2009/10/01. PubMed PMID: 23926469; PubMed Central PMCID: PMCPMC3719324.

19. Oko R, Maravei D. Distribution and possible role of perinuclear theca proteins during bovine spermiogenesis. Microsc Res Tech 1995; 32(6): 520-32. Epub 1995/12/15. PubMed PMID: 8605399. https://doi.org/10.1002/ jemt.1070320605.

20. Pinborg A, Hougaard CO, Nyboe Andersen A, Molbo D, Schmidt L. Prospective longitudinal cohort study on cumulative 5-year delivery and adoption rates among 1338 couples initiating infertility treatment. Hum Reprod 2009; 24(4): 991-9. Epub 2009/01/13. PubMed PMID: 19136480. https://doi.org/10.1093/humrep/ den463.

21. Sharlip ID, Jarow JP, Belker AM, Lipshultz LI, Sigman M, Thomas AJ, et al. Best practice policies for male infertility. Fertil Steril 2002; 77(5): 873-82. Epub 2002/05/16. PubMed PMID: 12009338. https://doi.org/10. 1016/s0015-0282(02)03105-9.

22. Vayena E, Rowe P, Griffin P. Current Practices and Controversies in Assisted Reproduction. Geneva: World Health Organization; 2002. p. 3-22.

23. Jungwirth A, Giwercman A, Tournaye H, Diemer T, Kopa Z, Dohle G, et al. European association of urology guidelines on male infertility: the 2012 update. Eur Urol 2012; 62(2): 324-32. Epub 2012/05/18. PubMed PMID: 22591628. https://doi.org/10.1016/j.eururo.2012.04.048.

24. Kovac JR, Pastuszak AW, Lamb DJ. The use of genomics, proteomics, and metabolomics in identifying biomarkers of male infertility. Fertil Steril 2013; 99(4): 998-1007. Epub 2013/02/19. PubMed PMID: 23415969; PubMed Central PMCID: PMCPMC3652543. https://doi.org/10.1016/j.fertnstert.2013.01.111.

25. WHO. WHO laboratory manual for the examination and processing of human semen, 5th ed. Switzerland: WHO press; 2010. ISBN:978 9241547789. 
26. Yin Y, Stahl BC, DeWolf WC, Morgentaler A. p53-mediated germ cell quality control in spermatogenesis. Dev Biol 1998; 204(1): 165-71. Epub 1998/12/16. PubMed PMID: 9851850. https://oi.org/10.1006/dbio. 1998.9074.

27. Kido T, Arata S, Suzuki R, Hosono T, Nakanishi Y, Miyazaki J, et al. The testicular fatty acid binding protein PERF15 regulates the fate of germ cells in PERF15 transgenic mice. Dev Growth Differ 2005; 47(1): 15-24. Epub 2005/03/03. PubMed PMID: 15740583. https://doi.org/10.1111/j.1440-169x.2004.00775.x.

28. Korley R, Pouresmaeili F, Oko R. Analysis of the protein composition of the mouse sperm perinuclear theca and characterization of its major protein constituent. Biol Reprod 1997; 57(6): 1426-32. Epub 1998/01/04. PubMed PMID: 9408250. https://doi.org/10.1095/biolreprod57.6.1426.

29. Sosnin DY, Galkovich KR, Zubareva NA, Krivtsov AV, Pozdin NV. Fatty Acid-binding protein, in the serum and sperm. Urologia 2019; 3: 95-100.

30. Pouresmaeili F, Morales CR, Oko R. Molecular cloning and structural analysis of the gene encoding PERF 15 protein present in the perinuclear theca of the rat spermatozoa. Biol Reprod 1997; 57(3): 655-9. Epub 1997/ 09/01. PubMed PMID: 9283004. https://doi.org/10.1095/biolreprod57.3.655. 